\title{
Systematic mechanical assessment of consolidants for canvas reinforcement under controlled environment
}

\author{
Alexandra Bridarolli ${ }^{1,2^{*}}\left(\mathbb{D}\right.$, Anna Nualart-Torroja ${ }^{3}$, Aurélia Chevalier ${ }^{4}$, Marianne Odlyha ${ }^{5 \dagger}$ and Laurent Bozec ${ }^{6+}$
}

\begin{abstract}
In conservation, adhesives are commonly used for the consolidation of canvases, yet their impact upon the canvas longevity has raised some concerns amongst conservators. As such, this study presents a testing protocol developed to assess the performance of commonly-used adhesives (natural animal glue and synthetic Beva ${ }^{\circledR} 371$ ) and a newly developed nanocellulose consolidant, nanofibrillated nanocellulose (CNF). This includes their effect on the visual appearance, consolidation, and response of the mechanical properties of the treated canvases to programmed changes in relative humidity (RH). Scanning electron microscopy (SEM) images of animal glue- and Beva ${ }^{\circledR} 371$-treated canvases revealed the presence of adhesive and consolidant on and in-between cotton fibres. The consolidants form bridges linking and connecting the cotton fibres and holding them together, whereas the CNF treatment, formed a visible continuous and dense surface coating. None of the treatments induced any discernible colour change. Controlled environment mechanical testing was performed in two ways: by applying a linearly increasing static force at fixed $\mathrm{RH}$ (Young's modulus) and by applying a dynamic force together with a programmed RH cycling between 20 and $80 \%$ (RH dependent viscoelastic properties). CNF gave a higher value of Young's modulus than either of the two commonly-used materials. Measurements at different values of RH (20 and 80\%) demonstrated for all the treated canvases that at the lower value (RH 20\%) Young's modulus values were higher than at the higher value (RH 80\%). Besides, the dynamic mode showed that the rate of response in all cases was rapid and reversible and that the nanofibrillated cellulose treated sample showed the highest variation in storage (or elastic) modulus measured at the end of $\mathrm{RH}$ plateaux ( 20 and $80 \% \mathrm{RH}$ ). Thus CNF appears to be a promising material given its higher mechanical performance. The protocol developed in this study has enabled us to examine and compare candidate materials for the consolidation of canvases systematically, using testing parameters that remained relevant to the field of canvas conservation.
\end{abstract}

Keywords: Canvas consolidation, Lining, Nanocellulose, Dynamic mechanical analysis (DMA), Relative humidity, Mechanical properties, Hygroscopicity

\section{Introduction}

Structural conservation of easel paintings has relied since the 18th and 19th centuries on the lining process, which consists of gluing a new canvas directly onto the back of the existing and failing canvas. The binding of this new

\footnotetext{
*Correspondence: abridarolli@getty.edu

${ }^{\dagger}$ Marianne Odlyha and Laurent Bozec senior authors

2 Getty Conservation Institute, 1200 Getty Center Dr \#700, Los Angeles,

CA 90049, USA

Full list of author information is available at the end of the article
}

canvas aims to provide further structural support to the original painting, hence increasing its lifetime. When the risks associated with traditional glue paste and wax-resin lining were publicized in the 1970s [1], several researchers such as Mehra [2], Berger [3] and Hedley [4] started to investigate less invasive lining techniques as well as alternative strategies to consolidate weakened canvases. As part of their research, they established several criteria and recommendations (physical, mechanical, and chemical) to direct their research to the most suitable adhesives and consolidants for the consolidation of painting
Springer Open

(c) The Author(s) 2020. This article is licensed under a Creative Commons Attribution 4.0 International License, which permits use, sharing, adaptation, distribution and reproduction in any medium or format, as long as you give appropriate credit to the original author(s) and the source, provide a link to the Creative Commons licence, and indicate if changes were made. The images or other third party material in this article are included in the article's Creative Commons licence, unless indicated otherwise in a credit line to the material. If material is not included in the article's Creative Commons licence and your intended use is not permitted by statutory regulation or exceeds the permitted use, you will need to obtain permission directly from the copyright holder. To view a copy of this licence, visit http://creativeco mmons.org/licenses/by/4.0/. The Creative Commons Public Domain Dedication waiver (http://creativecommons.org/publicdomain/ zero/1.0/) applies to the data made available in this article, unless otherwise stated in a credit line to the data. 
canvases. This work led to the development of new synthetic adhesives such as Beva ${ }^{\circledR}$ by Berger [3], for example. The original list of criteria selected for the evaluation of treatments for canvas consolidation included: acceptability to conservators (texture, handling, appearance); high stiffness; negligible hygroscopicity; resistance to creep and stress relaxation, durability; reversibility; low extensibility; good elastic recovery; good adhesion to chosen grounds; low cost; availability and ease-of-use to treat paintings of a large format. In 2015, an online survey of 67 conservators [5] conducted as part of the Nanorestart European project ${ }^{1}$ concluded that the current expectations and requirements of conservators for the developments of new consolidants for painting canvases had not changed since the 1970s. Those interviewed agreed that the essential criteria in choosing a consolidation product ought to be canvas strengthening, resilience to aging, and reversibility.

In contemporary conservation, the materials used for the consolidation of fragile painting canvases are either natural (e.g., animal glue) [6] or synthetic compounds (e.g., Beva ${ }^{\circledR}$ 371) [7-9]. The properties of these compounds have been well characterized, including their mechanical properties, which have been assessed by tensile testing $[4,10-14]$ and by measuring the adhesion between two canvases [15-17]. Further studies focussed on the impact of the ageing on the compound's overall mechanical properties (McGlinchey [18] on Beva ${ }^{\circledR} 371$; Feller [19] and Grassie [20] on acrylics glues; Horie [21] on poly (vinyl alcohol) polymers). However, it is still challenging to compare and benchmark the results of these numerous studies as the analytical techniques used vary from study to study. Interestingly, the mechanical response to relative humidity ( $\mathrm{RH}$ ) has been tested only for a few materials, although this property is considered essential for canvas consolidation. Amongst all the compounds used, animal glue and Beva ${ }^{\circledR} 371$ are two common adhesives used in painting conservation as lining adhesives. On rarer occasions, these two compounds have also been used to consolidate canvases by impregnation [6]. Yet, their mechanical assessment in painting conservation is limited to their assessment as lining adhesives [2, 3, 13, 22, 23]. Amongst the more recent materials suggested as consolidant or lining adhesive, nanofibrillated cellulose (CNF) has been the focus of several detailed studies $[24,25]$. Although this new material presents exceptional material properties, it is essential to review these properties in the context and parameters of canvases' lining approach and especially assess its response to relative humidity $(\mathrm{RH})$.

${ }^{1}$ http://www.nanorestart.eu/.
This study presents a systematic analytical approach to assess the physical and mechanical properties of consolidated canvases as a function of relative humidity. This approach was designed together with conservators to ensure that the parameters studied remained relevant to the task of canvas lining. This approach was successfully applied to compare the reinforcement of canvases by adhesives and canvas consolidants currently in use with that of a newly developed nanocellulose-based treatment. The measurement outcomes of this investigation were selected from the list of criteria for the evaluation of treatments for canvas consolidation, as defined by Hedley [26], Mehra [27], and Berger [3].

\section{Materials and methods} Commonly-used consolidants or lining adhesives

Following the advice and agreement with conservators experts in the lining process, two consolidants (or adhesives) were selected for this study: animal glue (natural consolidant) and vinyl acetate Beva ${ }^{\circledR} 371$ (synthetic consolidant). These materials are widely used for canvas consolidation and lining works [7-9, 28-30]. The animal glue used in this study was purchased from Lienzos Levante (Alicante, Spain) and consisted of a rabbit skin glue in pellets with a bloom strength of $340-360$. Beva ${ }^{\circledR} 371$ was purchased from CTS (Italy). It consists of an ethylenevinyl acetate copolymer, which is one of the most widely used synthetic compounds as lining adhesives [31].

\section{Nanocellulose}

Nanofibrillated cellulose (CNF) in the form of an aqueous suspension was provided by Stora Enso AB (Sweden). The CNF was produced from bleached kraft softwood pulp (ca. $75 \%$ of pine and $25 \%$ of spruce, containing $85 \%$ of cellulose, $15 \%$ of hemicellulose, and traces of lignin, as determined by the supplier) by sulfuric acid hydrolysis. Further details about this compound were recently published by Nechyporchuk [24]. Topographic images (NanoWizard I Atomic Force Microscope, Bruker, Santa Barbara-contact mode-MNSL probe) and the chemical structure of CNF are given in Fig. 1.

\section{Sample preparation}

In this study, all the consolidants were applied directly to single-sourced modern cotton canvas samples. The canvas used was a plain-woven fabric of $417 \pm 3 \mathrm{~g} / \mathrm{m}^{2}$ purchased in Barna Art (Barcelona, Spain). It consists of 9 and 11 threads $/ \mathrm{cm}$ in the warp and weft directions, respectively. Series of $10 \mathrm{~cm} \times 10 \mathrm{~cm}$ cotton canvas samples were artificially degraded for 3 days in a solution of hydrochloric acid at $95-98 \%(10 \mathrm{~mL})$ and hydrogen peroxide at $35 \%$ wwt $(200 \mathrm{~mL})$ at $40{ }^{\circ} \mathrm{C}$ following a protocol given described elsewhere [33]. The degradation process 


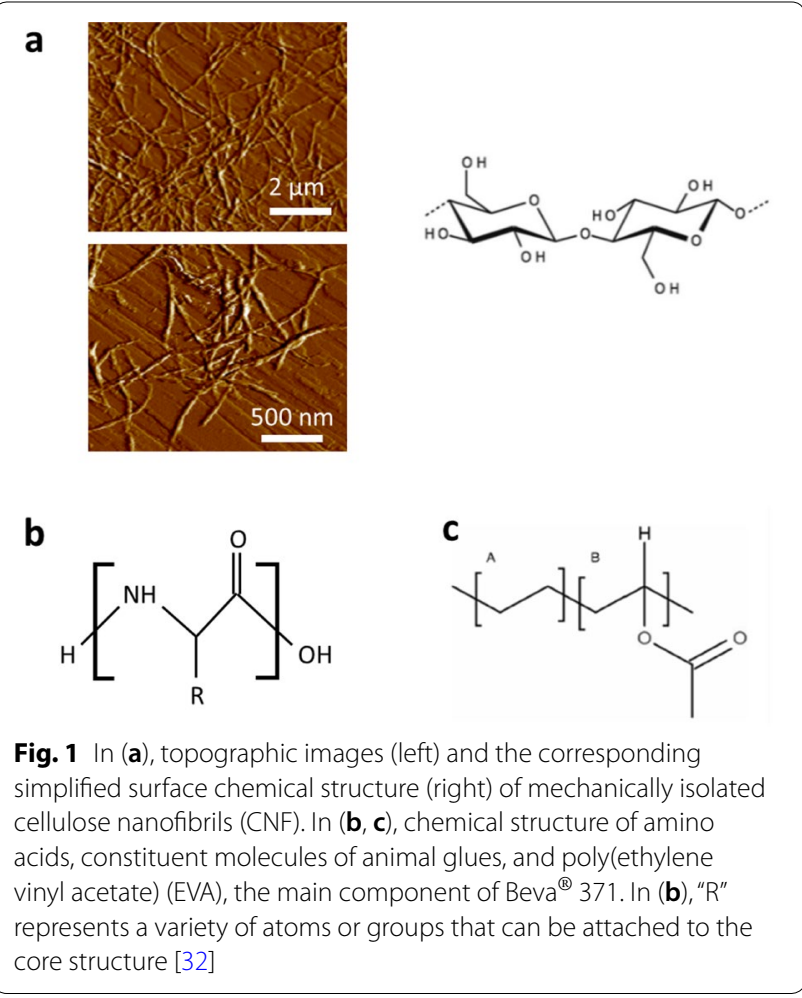

reduced the density of the canvas from 417 to $374 \mathrm{~g} / \mathrm{m}^{2}$. The degraded samples were then treated (consolidated) by a team of experienced painting conservators at the University of Barcelona (Spain) to ensure optimal application of the treatments. Three consolidants were used independently for the treatment of the degraded canvas samples: Beva ${ }^{\circledR} 371$ (in white spirit) and aqueous preparations of animal glue, and nanofibrillated cellulose CNF (Table 1). Before any application treatment, each canvas sample was weighed and subsequently mounted on a wooden frame to mimic consolidation conditions. The consolidation treatments were then applied by brush to reach a weight increase between 3.4 and $4.6 \%$, as reported in Table 1. The conservators chose the solvent and dilutions used for each product based on the best-practices values used in conservation for each adhesive. Depending on the viscosity of the consolidant, either a single or multiple layers of consolidant were applied onto the canvas to reach the targeted $4 \%( \pm 1 \%)$ weight increase. The adhesive was left to dry in ambient conditions between each application. It is worth mentioning that in the case of real paintings, it would be better to apply the consolidants with several sprayed coats to minimize the adverse effects that the solvents could have on the canvas and the ground and paint layers. However, in this study, we opted to use a brush to control better the amount of adhesive added to each sample. In our approach, the application of the treatments required solvent quantities that will need to be revised and ought to be the subject of a separate study on adverse effects.

\section{Structural analysis}

The structural analysis of the treated samples was carried out using a Philips XL30 field emission scanning electron microscope SEM (FEI, Eindhoven, Netherlands). The system was operated at $5 \mathrm{kV}$ accelerating voltage. Samples $(3 \times 5 \mathrm{~mm})$ were mounted on aluminium stubs (Agar Scientific, Essex, UK) and sputtered with Gold/Palladium using a Polaron E5000 sputter coater for 1min30s.

\section{Colourimetry}

The colourimetric assessment of pre-post treated samples was performed using an X-Rite 530 Colourimeter (X-rite-Switzerland). The colour change was calculated according to the CIEL"a*b" colour space:

$$
\Delta E^{*}=\sqrt{\Delta L^{* 2}+\Delta a^{* 2}+\Delta b^{* 2}}
$$

where $L$ is lightness, $\mathrm{a}^{*}$ is the red-green component, $\mathrm{b}^{*}$ is the yellow-blue component (for the D65/10 CIE Illuminant/observer condition). For each sample, 10 data points were collected over an area of $8 \times 8 \mathrm{~cm}^{2}$ located in the centre of the canvas samples.

Table 1 List of the samples used in this study and treatments applied to the degraded cotton samples

\begin{tabular}{llllll}
\hline Treatment and sample & $\mathbf{w / v}$ & solvent & $\begin{array}{l}\text { Surface deposition (g/ } \\
\mathbf{m}^{\mathbf{2}} \mathbf{l}\end{array}$ & $\begin{array}{l}\text { Number of layers } \\
\text { applied }\end{array}$ & Added weight \\
\hline $\begin{array}{l}\text { Untreated degraded cotton canvas } \\
\text { CNF }\end{array}$ & $1 \%$ & Water & 11.7 & 4 & $3.4 \%$ \\
Animal glue & $1.7 \%$ & Water & 15.7 & 2 & $4.6 \%$ \\
Beva 371 & $3 \%$ & White spirit & 13.7 & 4 & $4.0 \%$ \\
\hline
\end{tabular}




\section{Mechanical analysis \\ Tensile measurement}

The treated cotton samples and the non-treated control sample were sectioned in rectangles of the following dimensions: 0.7 (thickness) $\times 7$ (width) $\times 15$ (length) $\mathrm{mm}$ to ensure that precisely ten threads were present in the warp direction. Tensile testing measurements were performed using Dynamic Mechanical Analysis (DMA Tritec 2000B, Lacerta Technology, UK)-operated in static tensile mode. Before starting the measurements, the samples were preconditioned at a fixed $\mathrm{RH}$ level for the tensile test $(20$ or $80 \% \mathrm{RH})$ for a minimum of $48 \mathrm{~h}$. The samples were mounted in tension and subjected to a static load increasing at the rate of $0.4 \mathrm{~N} / \mathrm{min}$. The free length of the mounted canvas $(5 \mathrm{~mm})$ in the DMA was exposed to two fixed relative humidity environments $(20 \% \mathrm{RH}$ and $80 \% \mathrm{RH})$ at a fixed temperature $\left(25^{\circ} \mathrm{C}\right)$ controlled by circulating water bath to investigate the effect of RH on the mechanical performance of the samples before and after consolidation. The Young's modulus $(E)$ values were calculated from the slopes of the stressstrain curves.

\section{Dynamic mechanical analysis under controlled programmed $R H(D M A-R H)$}

Another set of samples (as prepared for the tensile measurements) was characterized using Dynamic Mechanical Analysis (Tritec 2000B, Lacerta Technology, UK)-operated in dynamic mode and connected to a humidity generator. Before starting the measurements, the samples were preconditioned for at least $48 \mathrm{~h}$ at $20 \% \mathrm{RH}$, before being mounted in the DMA. The samples were subjected to a preload of $1 \mathrm{~N}$ at the start of each measurement cycle to overcome any buckling resulting from the woven structure of the samples. The free length of the mounted canvas $(5 \mathrm{~mm})$ in the DMA was subjected to sinusoidal stress $(1 \mathrm{~Hz})$ while being exposed to variable relative humidity environments at a fixed temperature $\left(25^{\circ} \mathrm{C}\right)$. At the start, the $\mathrm{RH}$ was rapidly cycled at $4 \% \mathrm{RH} / \mathrm{min}$ to $60 \%$ $\mathrm{RH}$, left at $60 \% \mathrm{RH}$ for 5 min before being reduced to $20 \%$ $\mathrm{RH}$ (mechanical conditioning as shown in Fig. 2) to overcome any issue related to the mechanosorptive creep, i.e., increase in creep rate under cyclic humidity conditions already shown to occur for hydrophilic fibrous materials such as wood pulp paper, cotton paper and nanocellulose $[34,35]$. This was followed by the $\mathrm{RH}$ cycling program, which consisted of cycles going from 20 to $80 \%$ $\mathrm{RH}$ at $4 \% \mathrm{RH} / \mathrm{min}(20$ to $60 \% \mathrm{RH})$ and $2 \% \mathrm{RH} / \mathrm{min}(60$ to $80 \% \mathrm{RH}$ ) and back to $20 \% \mathrm{RH}$ at $4 \% \mathrm{RH} / \mathrm{min}$. The $\mathrm{RH}$ was maintained constant for $30 \mathrm{~min}$ at 20 and $80 \% \mathrm{RH}$ for each cycle (Fig. 2). This RH cycle (20\% to $80 \%$ to $20 \%$ $\mathrm{RH}$ ) was repeated 3 times, as shown in Fig. 2. Values for

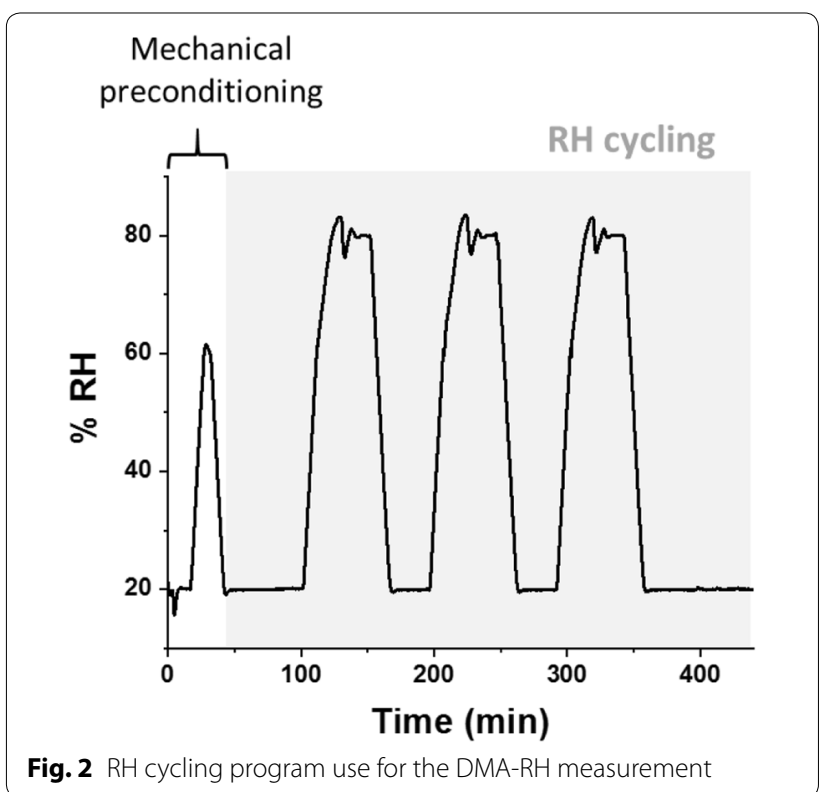

both the elastic ( $E^{\prime}$ stored energy) and viscous ( $E$ " dissipated energy) components of the complex modulus were calculated from the DMA data.

\section{Results and discussion Appearance}

The first assessment carried on the degraded samples involved measuring any perceptible change in the colour of the canvas as a result of the treatment. Although the original canvas had a beige colour, its degradation (mostly by $\mathrm{H}_{2} \mathrm{O}_{2}$ ) strongly whitened its surface, as seen in Fig. $3 \mathrm{~b}$ by the increase in $L^{*}$ value after aging $\left(\Delta L^{*}=L^{*}\right.$ not degraded $L^{*}$ degraded $\left.<0\right)$. As presented in Fig. 3a, the colour variation $\Delta E^{*}$ measured between treated and untreated (degraded) cotton canvas remains below 3 (highlighted in red). Below this value, any colour change is considered as minimal and only perceptible for expert eyes or when the two colours compared are placed next to another [36], which is the case for all the treated samples.

The surface of the canvas samples was also imaged by SEM to evaluate the surface coverage and penetration of the treatments when applied onto the woven fabric. Figure 4 shows that the commonly used consolidants animal glue and Beva ${ }^{\circledR} 371$ are not easily visible on the canvas surface when imaged at low magnification (i.e., between $\times 35$ and $\times 40$ ). At higher magnification, the presence of consolidant on and in-between cotton fibres can be observed for animal glue- and Beva ${ }^{\circledR}$ 371-treated canvases. The consolidants are forming bridges linking and connecting the cotton fibres and holding them together. The CNF treatment, however, forms a continuous and dense surface coating visible at both low and 

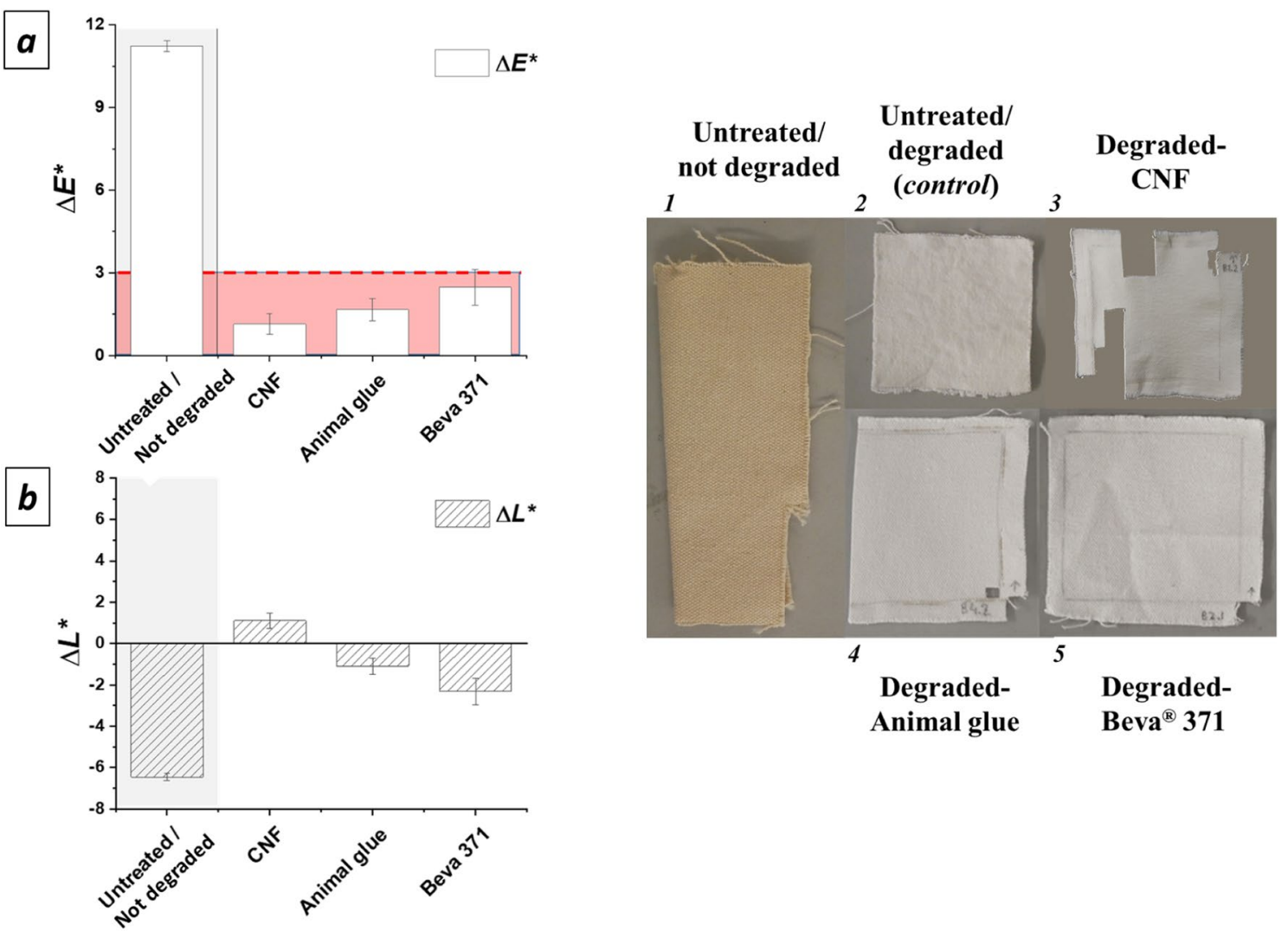

Fig. 3 On the left, using the untreated degraded cotton canvas as a reference, colour difference $\Delta E^{*}(\mathbf{a})$ and difference in lightness $\Delta L^{*}$ (b) measured for the not degraded untreated cotton canvas (( 1 ) on the right) and for the degraded cotton canvas (2) after the application of the nanocellulosic treatment CNF (3) and two commonly-used adhesives/consolidants used in painting conservation, animal glue (4) and Beva ${ }^{\circledR} 371$ (5)

high magnification, as shown in Fig. 4. The threads and fibrils of the underlying canvas are still visible after the application of the treatment suggesting that the coated layer is very thin. The weaving pattern of the threads and
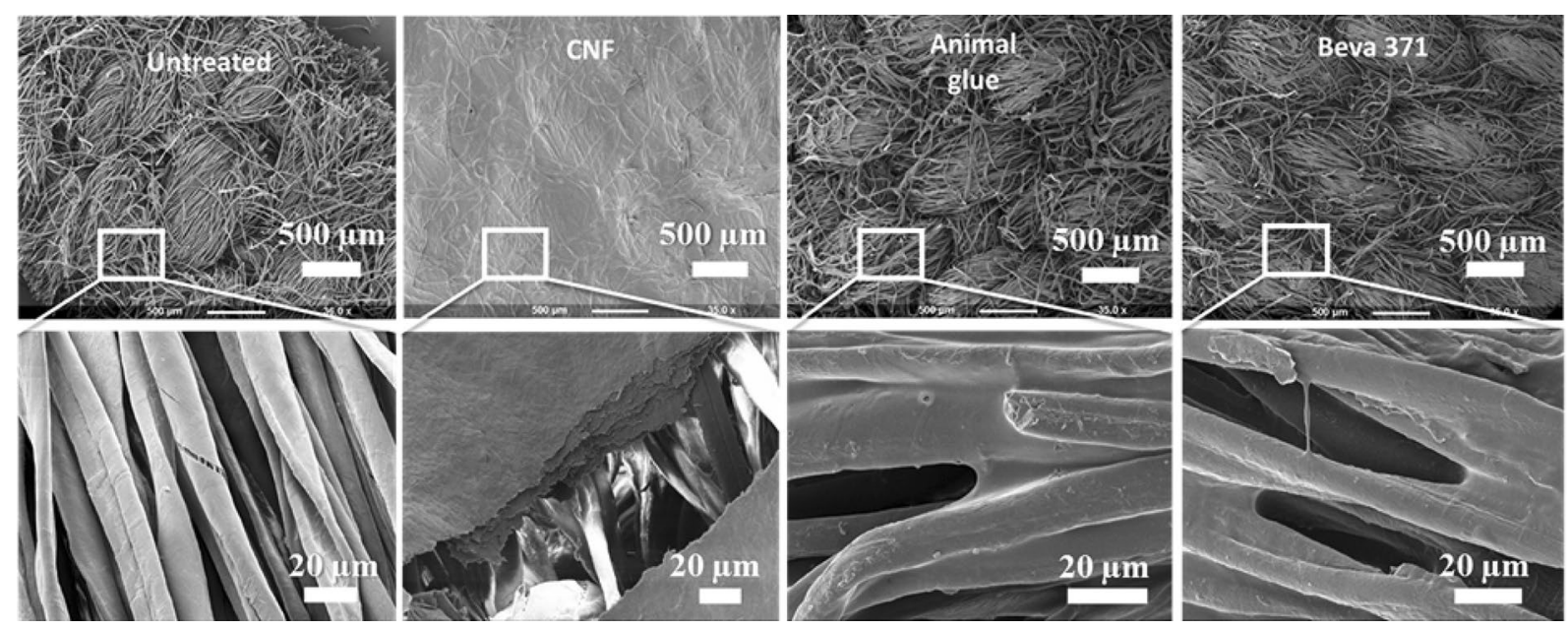

Fig. 4 SEM images of the surface of the degraded cotton canvas untreated and treated with CNF, animal glue and Beva ${ }^{\circledR} 371$ shown at 2 different magnifications 


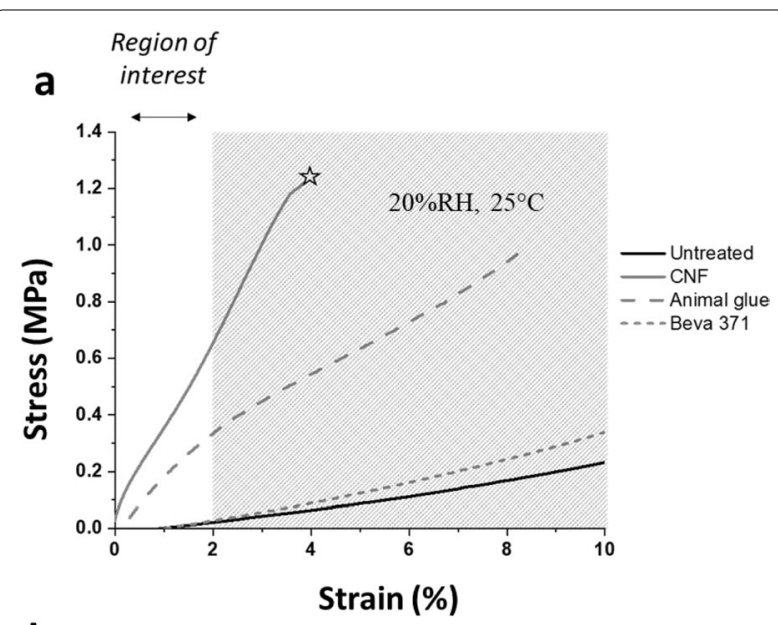

b

\begin{tabular}{|c|c|}
\hline Sample & $\begin{array}{c}\text { Young's modulus } E \text { (MPa) } \\
\left(20 \% R H, 25^{\circ} \mathrm{C}\right)\end{array}$ \\
\hline Untreated & $1.8 \pm 0.2$ \\
\hline CNF & $23.1 \pm 1.8$ \\
\hline Animal glue & $14.3 \pm 2.1$ \\
\hline Beva 371 & $3.8 \pm 0.8$ \\
\hline
\end{tabular}

Fig. 5 Stress and strain curves (a) obtained at $20 \% \mathrm{RH}\left(25^{\circ} \mathrm{C}\right)$ for the degraded cotton canvas (warp direction) before and after treatment using the newly developed CNF consolidant and 2 adhesives commonly used in conservation, animal glue and $\mathrm{Beva}^{\circledR} 371$. The Young's moduli calculated from the region of interest (i.e. $1-2 \%$ in elongation) are given in the table in (b). The star marks a sudden loss in canvas stiffness measured for the CNF-treated sample only

cotton fibres is mostly covered with the treatment: the nanocellulose layer covers the interstices and voids seen between the threads of the untreated sample. The coated surface appears homogeneously flat and impermeable. This surface behaviour specific to the CNF treatment is favourable for canvas reinforcement as it is known that impregnating a canvas can cause it to shrink or change its shrinkage properties [22, p.95].

\section{Tensile reinforcement}

Following the visual assessment of the samples, the overall reinforcement provided by the various consolidants was measured by tensile testing, as presented in Fig. 5 . The capacity of the products to reinforce the canvas was evaluated by determining if the added products improved the stiffness and resistance to elongation of the canvas. The canvas must support the ground and paint layers and limit the movements of these rigid layers to avoid permanent deformation that occurs long before the formation of cracks [37]. The tensile tests were performed at both 20 and $80 \% \mathrm{RH}$ since it is well-known that moisture $(\mathrm{RH})$ can greatly influence the mechanical response of materials encountered in paintings. This result was previously demonstrated for linen canvases $[4,13,37]$ which present an increased stiffness above $75 \% \mathrm{RH}$ due to the swelling of the threads or lining adhesives while animal glue or cellulose ethers lose their strength with increasing $\mathrm{RH}$ [37].

As shown in Fig. 5, the application of all the consolidation treatment led to a net increase in stiffness of the treated degraded cotton canvases. This stiffening (increase in Young's Modulus) was measured as an increase in the slope of the stress-strain curves measured in the region of interest, i.e. between 1 and $2 \%$ in elongation, values to which canvases are commonly stretched [12]. Among all the treatments tested, the largest increase in stiffness in the region of interest was obtained for the nanocellulose-based treatment, CNF. An increase in $E$ from $1.8 \pm 0.2 \mathrm{MPa}$ (untreated canvas) to $23.1 \pm 1.8 \mathrm{MPa}$ (i.e., around 13 times higher) was measured for the CNF-treated sample (Fig. 5). Nechyporchuk [24] has measured a similar increase between unprimed and primed degraded cotton canvases (i.e., by 20 times from 17.6 MPa to $356 \mathrm{MPa}$ ) tested in the weft direction.

In an easel painting, the paint and ground layers are usually far stiffer than the canvas. However, these layers can act as support layers for the painting when the canvas becomes too fragile and is unable to fulfill its role of support [12]. Hence, a mechanical relationship must exist between the canvas and the paintings for it to act as support material. In essence, a canvas can only really support a painting if its stiffness matches that of the painting. Therefore, the level of reinforcement obtained with the CNF treatment is such that it offers adequate support to the ground and paint layers of similar stiffness. The increase in stiffness measured for the commonly-used consolidants, Beva ${ }^{\circledR} 371$, and animal glue remains, in comparison, lower than that obtained for the CNF treated sample. Overall, for the same weight added, the nanocellulosic treatment offers a more effective consolidation at low $\mathrm{RH}$ as it provides support to the canvas. Similar observations and results were also obtained for the tests performed at $80 \% \mathrm{RH}$. The results for the $80 \%$ RH tests can be found in Fig. 6 .

Overall, the tensile consolidation provided by the commonly-used and nanocellulose consolidants is maintained even at high RH. Again, it is the nanocellulose treatment that provided the largest increase in tensile stiffness when compared to the commonly-used consolidants. This is also true when correction factors associated with the sample thickness are introduced in the calculation of the stresses shown in Figs. 5 and 6. Indeed, the cross-sectional area of textiles contains a large amount of voids due to the weaving that will impact on the overall mechanical response of the canvas. For this reason, the 


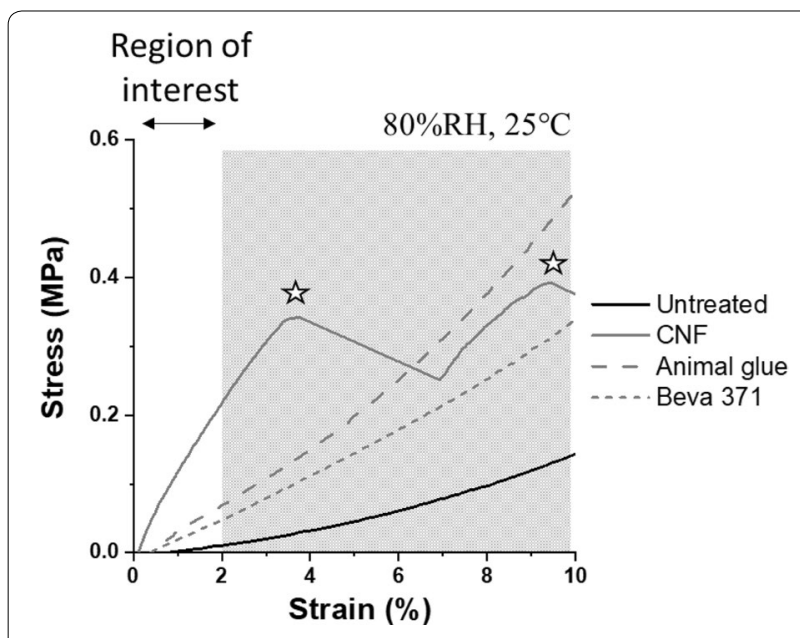

Fig. 6 Stress and strain curves obtained at $80 \% \mathrm{RH}, 25^{\circ} \mathrm{C}$ for the degraded cotton canvas untreated and treated with CNF, animal glue and Beva ${ }^{\circledR}$ 371. The two stars indicate sudden loss in sample stiffness which are associated with localized rupture of the brittle CNF superficial film

results of the mechanical assessment or modelling of the canvas have often been reported in terms of load (excluding dimensions) [3] or taking into account a correction factor for the canvas thickness [38]. In the current case, the low penetration observed for the CNF treatment when compared to the animal glue and Beva ${ }^{\circledR} 371$ treatment leads to the presence of a higher number of voids in the canvas post-treatment compared to the other two. This would result in an increase in the effective thickness and related subjected stress in the case of the CNF treated sample when compared to the other two treated samples (in which the treatment penetrated within the canvas). The non-linear behaviour of the stress-strain curves for the CNF-treated sample was observed above $2 \%$ of extension, whereas this was not observed for either of the commonly-used consolidants (Figs. 5 and 6). The phenomenon had already been reported by Nechyporchuk [24] and Bridarolli [25] for nanocellulose-treated canvases and was attributed to localized rupture of the coating, or nano lining, formed by the CNF on the canvas surface (Fig. 4).

\section{Hygroscopicity: static mechanical response to moisture}

The static mechanical response of the untreated and treated canvases as a result of $\mathrm{RH}$ variations was also evaluated. An example of tensile curves measured at 20, and $80 \% \mathrm{RH}$ for the animal glue-treated sample is shown in Fig. 7a. Curves of similar shapes were obtained for all consolidants. In this approach, it is the variation of Young's moduli as a function of the RH that ought to be considered. In Fig. 7b, one can observe that the increase in $\mathrm{RH}$ is responsible for a loss in Young's modulus (or
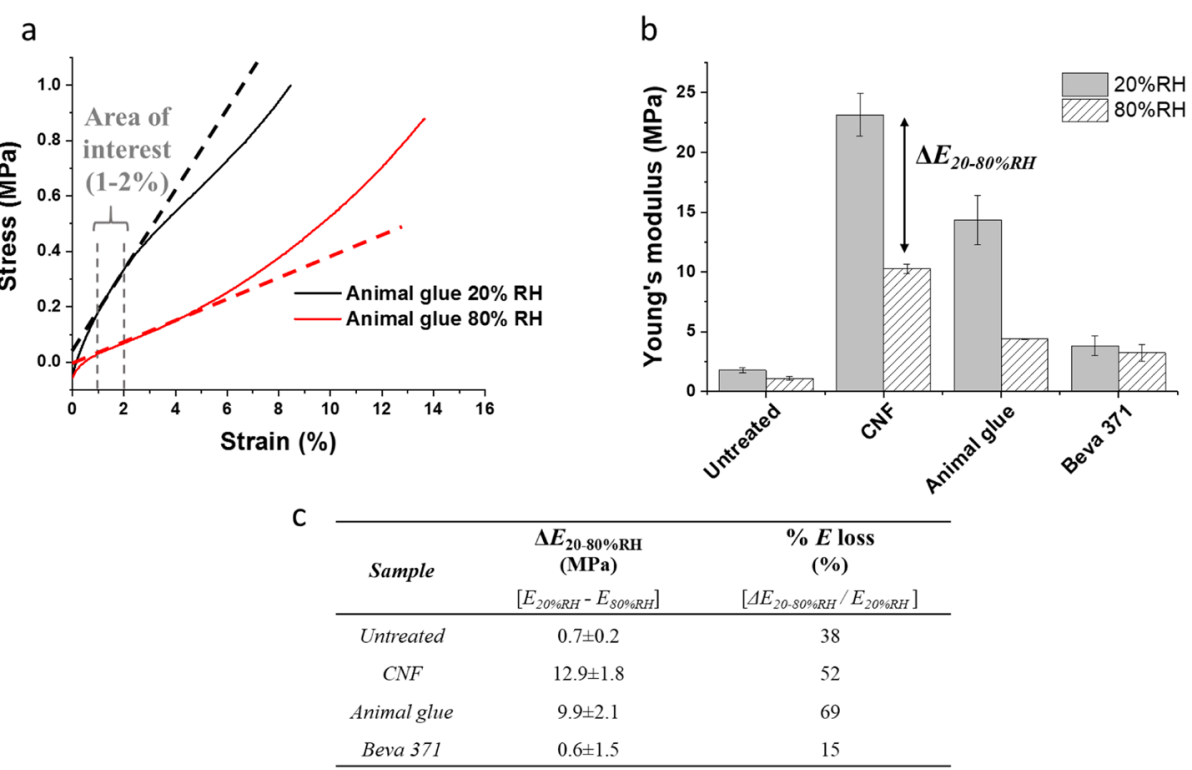

Fig. 7 In (a), tensile curves (solid lines) obtained at 20 and 80\% RH for the animal glue-treated degraded cotton canvas tested in the warp direction Linear fitting (dashed lines) of the curves was carried in the region of interest and used to calculate Young's moduli shown in (b). Young's moduli are given for degraded cotton canvas before and after treatment with CNF, animal glue and Beva ${ }^{\circledR} 371$ measured at 20 and $80 \%$ RH. The difference $\Delta E_{20-80 \% ~ R H}$ calculated between Young's moduli measured at 20\% RH (i.e., $E_{20 \% \text { RH }}$ ) and $80 \%$ RH (i.e., $E_{80 \% ~ R H}$ ) for untreated and treated degraded cotton canvases are tabulated in (c) 
decrease in stiffness) as measured for all the canvas samples, untreated or treated.

It has been argued that the plasticization of natural fibres at higher $\mathrm{RH}$ values results from water diffusion in the fibres [39-42]. As water molecules quickly diffuse in the amorphous regions of the cellulose fibres, hydrogen bonding between cellulose chains is replaced by watercellulose hydrogen bonding [40]. The structure formed by the cellulose chains and their packing is disrupted and this would cause the loss observed in mechanical properties of the untreated cotton canvas. At high RH levels, the cotton canvas becomes, therefore, more flexible and compliant. It is assumed that a very similar process might occur in the adhesives. In the latter case, losses in the stiffness of the materials might also be associated with a reduction in the interfacial adhesion between adhesive and cellulose fibres. This effect was observed by Bowditch [43] in a study on the performance of epoxy-based adhesive joint for wood exposed to water.

The decrease in Young's moduli $(E)$ at higher RH varies. As such, losses in $E$ range from $0.6 \pm 1.5$ to $9.9 \pm 2.1 \mathrm{MPa}$ were measured for the Beva ${ }^{\circledR} 371$ and animal gluetreated canvas, respectively (Fig. 7c). As expected, the animal glue is more sensitive to water moisture, i.e., more hygroscopic, than Beva ${ }^{\circledR} 371$. This is because the protein chains of animal glues contain a higher number of hydroxyl groups on the surface of their polymeric chains (see Fig. 1), which makes them more responsive to moisture and more prone to interact with the water molecules through hydrogen bonding $[44,45]$. This leads to a significant loss in $E$ of 69 (Fig. 7c) measured for this sample as opposed to Beva ${ }^{\circledR} 371$ (cyclohexane-based) associated with a loss in $E$ of only $15 \%$.

In comparison, the nanocellulose-treated canvas, which is also the stiffest canvas sample, registers the highest loss in $E$ (Fig. 7b). A loss from $23.1 \pm 1.8$ ( $E$ at $20 \% \mathrm{RH}$ ) to $10.3 \pm 0.4$ ( $E$ at $80 \% \mathrm{RH})$ was observed for the CNFtreated cotton canvas. These losses are equivalent to a decrease of approximately $52 \%$ in stiffness. This is likely due to the higher hygroscopic behaviour of nanocellulose than natural fibres such as cotton. It has been previously shown that depending on the preparation method, the specific surface area of CNF nanofibrils can approach $500 \mathrm{~m}^{2} / \mathrm{g}[46,47]$, while the specific surface area of soft cellulose pulp typically ranges between 1 and $4 \mathrm{~m}^{2} / \mathrm{g}$ [48]. This increase in surface area is related to an increase in the availability of the hydroxyl groups on the surface of nanocellulose, leading to higher hygroscopicity.

\section{Dynamic mechanical response to moisture variations}

In a second step, the mechanical response of the samples to moisture was also measured dynamically using $\mathrm{RH}$ variations and DMA. $\mathrm{RH}$ was programmed to vary

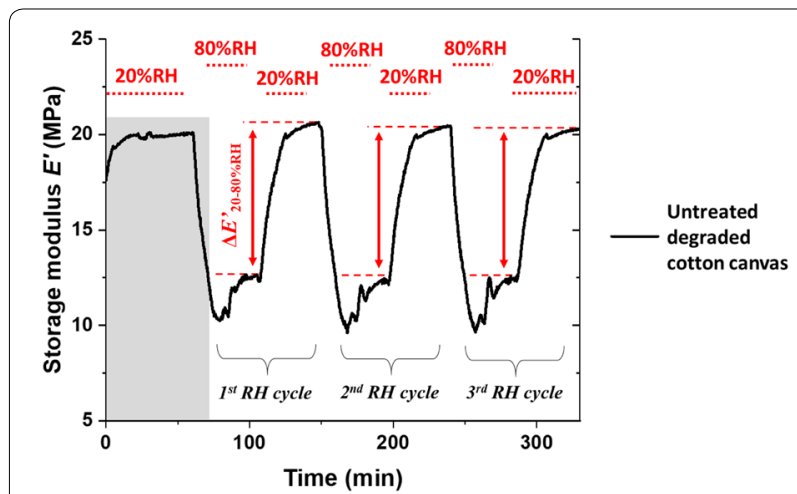

Fig. 8 DMA-RH curve obtained for an untreated degraded cotton canvas, tested in the warp direction, submitted to $3 \mathrm{RH}$ cycles $(20-80-20 \% \mathrm{RH}) . \Delta E_{20-80 \% \mathrm{RH}}^{\prime}$ is calculated from the end-plateaux values of $E^{\prime}$ at 20 and $80 \% \mathrm{RH}$ at each $\mathrm{RH}$ cycle

between 20 and $80 \% \mathrm{RH}$, the same humidity levels used for the tensile tests. The advantage of the DMA$\mathrm{RH}$ measurement over static tensile testing is that it enables measuring the real-time response of the same sample at different $\mathrm{RH}$ and during $\mathrm{RH}$ transitions in a non-destructively manner. The sample is measured under small deformation in its elastic region. An example of the mechanical response of a Beva ${ }^{\circledR}$ 371-treated canvas measured by DMA-RH upon the use of a $20-80 \% \mathrm{RH}$ humidity program is presented in Fig. 8 . The first $20 \% \mathrm{RH}$ should always be discarded in the analysis of the DMA$\mathrm{RH}$ curves as the first $20-80 \% \mathrm{RH}$ transition is associated with the mechanosorptive creep of the canvas and can be a source of errors.

As seen in Fig. 8, the response of the untreated and degraded cotton canvas sample is characterised by an increase in storage modulus $E^{\prime}$ at low $\mathrm{RH}$ level $(20 \%$ $\mathrm{RH})$ and decrease in $E^{\prime}$ at high $\mathrm{RH}$ level $(80 \% \mathrm{RH})$. This suggests that the treated canvas responds readily and reactively to $\mathrm{RH}$ variations by showing a lower viscoelastic behaviour (hence becoming stiffer) at low $\mathrm{RH}$ and a higher viscoelastic behaviour at high $\mathrm{RH}$. The canvas samples treated with animal glue, Beva ${ }^{\circledR} 371$ and $\mathrm{CNF}$ also responded similarly. Representative DMA-RH curves for the canvases treated with the commonly-used treatments and the CNF treatment are given in Fig. 9.

As seen in Fig. 9, the untreated and treated degraded cotton canvases absorb moisture at different rates depending on whether they are in $\mathrm{RH}$ ramping or under steady-state conditions (i.e. $\mathrm{RH}$ equilibration at 20 or $80 \% \mathrm{RH})$. The differences in $E^{\prime}$ measured between $\mathrm{RH}$ plateaux at 20 and $80 \% \mathrm{RH}$ (end-plateaux values) for the 2 nd RH cycle are plotted in Fig. 10. The results present similar trends to those obtained by tensile tests shown in Fig. 7. 

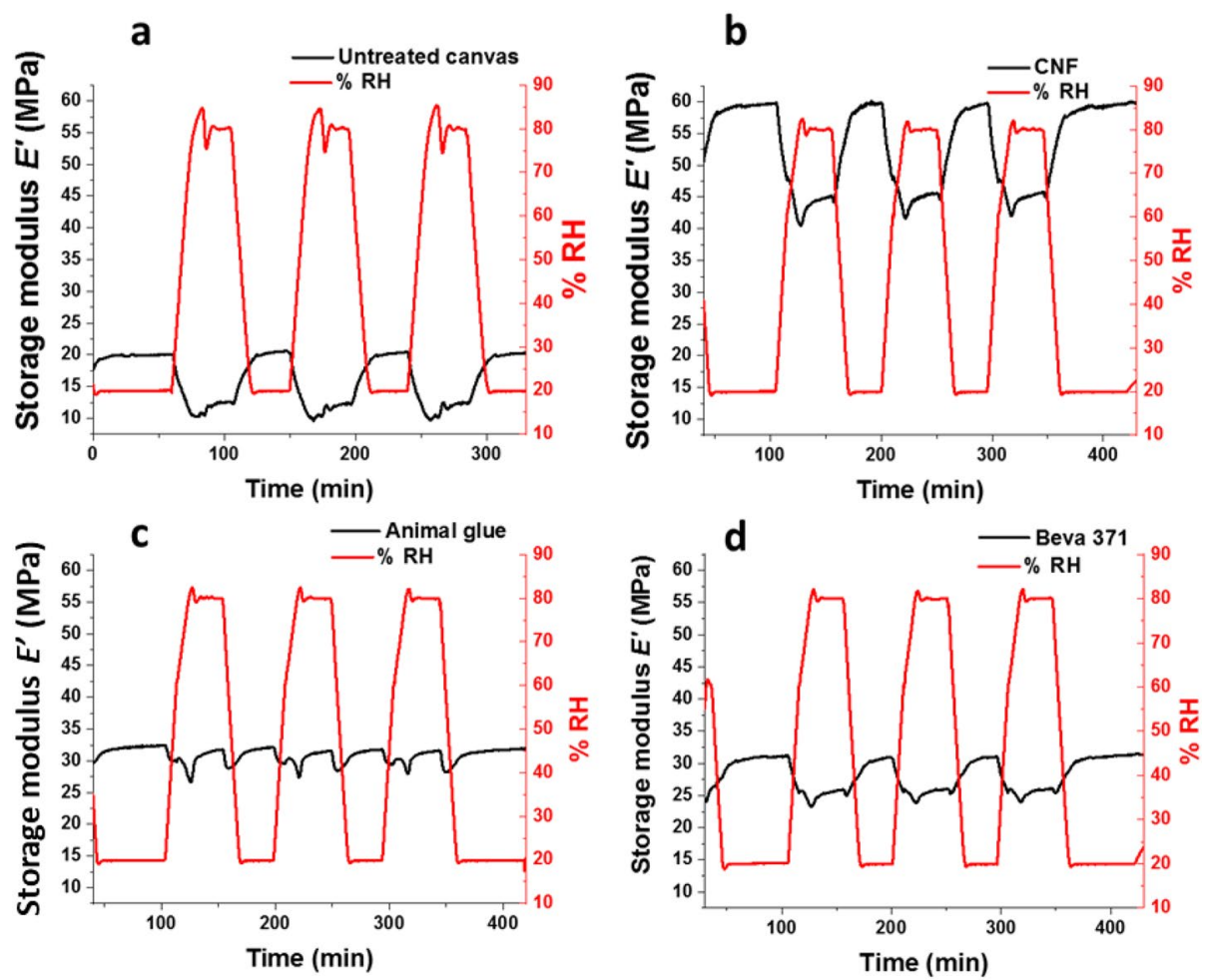

Fig. 9 DMA-RH curves (in black) obtained using the 20-80-20\% RH RH program (in red) on degraded cotton canvases untreated (a) and treated by brushing with CNF (b) and consolidants commonly-used in painting conservation, animal glue (c) and Beva ${ }^{\circledR} 371$ (d) (3\% total added weight)

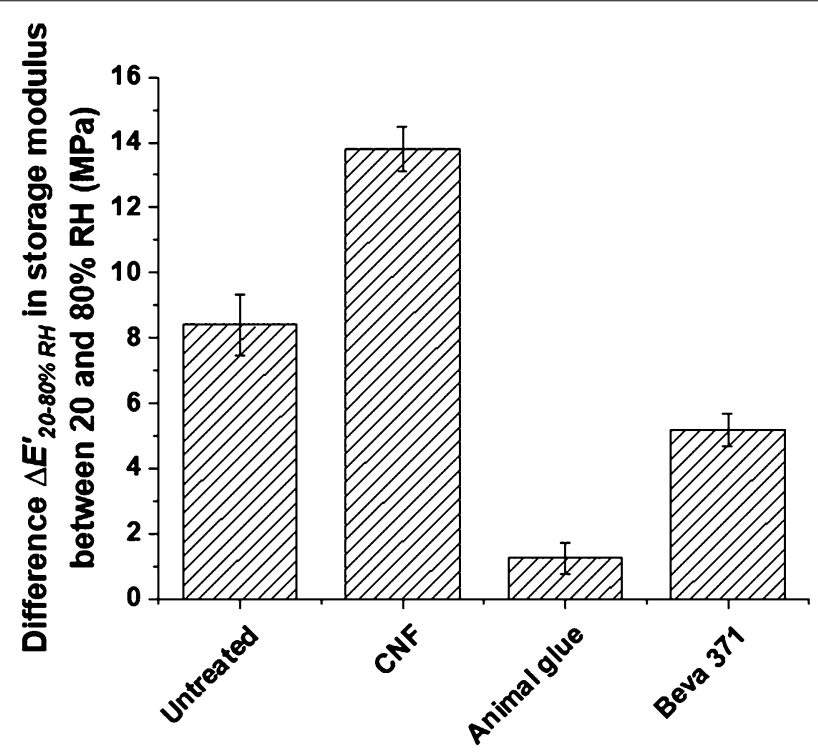

Fig. 10 Difference $\Delta E_{20-80 \% ~ R H}^{\prime}$ in storage modulus $E^{\prime}$ between the 20 and following $80 \% \mathrm{RH}$ plateaux (end-plateau values for 2nd RH cycle)

High variations in $E^{\prime}$, between the 20 and $80 \% \mathrm{RH}$ plateaux were measured for the CNF nanocellulose consolidant $\left(\Delta E_{2 n d}^{\prime} \quad\right.$ cycle $\left.=13.8 \pm 0.7 \quad \mathrm{MPa}\right)$. However, the high mechanical response to moisture of the 
animal glue-treated canvas, which had been measured by tensile testing was not observed when measuring the sample by DMA-RH under $20-80 \% \mathrm{RH}$ variations. The canvas sample treated with animal glue showed a lower mechanical response to moisture variations than the less hygroscopic consolidants, Beva ${ }^{\circledR}$ 371. A difference in $E^{\prime}$ between 20 and $80 \% \mathrm{RH}$ plateaux of $\Delta E_{2 n d \text { cycle }}^{\prime}=1.67 \pm 1.25 \mathrm{MPa}$ was obtained for the animal glue-treated canvas compared to $\Delta E_{2 n d}^{\prime}$ cycle $^{2} 5.57 \pm 0.7 \mathrm{MPa}$ for the Beva ${ }^{\circledR} 371$-treated one. Yet, tensile tests in section Fig. 7 had shown that the mechanical response of the animal glue-treated canvas was, with the nanocellulose-treatment $\mathrm{CNF}$, larger than the other commonly-used consolidant Beva ${ }^{\circledR} 371$.

This difference in the results obtained under static or dynamic exposure of the samples to moisture might result from the higher time of response to moisture (i.e. lower moisture diffusion) of animal glue in comparison with CNF.

\section{Conclusion}

This study was carried out to understand the impact of relative humidity on the mechanical properties of two consolidants commonly-used for painting canvas consolidation, animal glue, and Beva ${ }^{\circledR}$ 37. It also enabled the comparison of these materials with a newly-developed nanocellulose-based canvas consolidant, CNF. To date, this is one of the few studies that systematically links the performance of the consolidants to their mechanical properties, with a strong focus on the evaluation of their responses to moisture changes. This study established a systematic approach for the assessment of materials for canvas consolidation since we ensured that all measurement parameters and preparation techniques were relevant to canvas consolidation and conservation. Differences in the surface deposition of the consolidant, associated with treatment penetration, were observed between the three consolidants investigated: the commonly-used consolidants managed to cover individual cotton fibres and threads forming interfibrillar bridges, whereas the CNF remained as a layer on top of the canvas. The results of this study also highlighted the higher stiffness reached with the nanocellulose-based consolidant than with animal glue and Beva ${ }^{\circledR} 371$. CNF considerably improved the stiffness of the canvas, which is essential for the preservation of a painting. This reinforcement was also maintained at $80 \% \mathrm{RH}$. In comparison, animal glue-treated lost its canvas reinforcement capabilities at $80 \% \mathrm{RH}$ and at values under $40 \% \mathrm{RH}$, the glue contraction could cause permanent deformation of the ground and paint layers [36]. This result also indicates that among commonlyused consolidants, the more hygroscopic treatments, $\mathrm{CNF}$ and animal glue, are mechanically responsive to $\mathrm{RH}$ variations making them less suitable candidates for longterm consolidation. Interestingly, under fast RH cycling, the time-dependency of the mechanical response seemed to prevail for animal glue in comparison with CNF leading to lower apparent mechanical response of the animal glue treated canvas. The CNF treatment could also be considered highly brittle as a result of its film-forming behaviour on the canvas surface and lack of penetration. The contact area between CNF treatment and canvas fibres is low, which increases the risks that localized rupture of the coating might cause mechanical failure of the general reinforcement it provides. The potential risks associated with its brittle behaviour and its tendency to form a film when applied on a canvas could be one of the main limitations to promote CNF as a canvas consolidant. Further research is needed to find a solution to overcome this drawback. Alternatively, this superficial layer could also potentially avoid canvas shrinkage observed for impregnated canvases and offer good reversibility, which also needs to be further investigated.

Despite the growing need for prolonging the lifetime of easel paintings by canvas consolidation, there are no standard protocols established to evaluate the merits of new candidate materials. As such, conservators follow a set of guidelines. The uniqueness and relative complexity of each canvas restoration project also complicate the creation of a standard protocol. However, studies as the one presented here may constitute a first potential milestone in the establishment of standardized protocols, such as ISO standard for materials testing in conservation. This is an essential step to ensure the systematic assessment and benchmark the performance of various materials used in conservation in order not to repeat and propagate the mistakes of the past.

\section{Abbreviations}

CNF: Nanofibrillated cellulose; DMA: Dynamic mechanical analysis; DMA-RH: Dynamic mechanical analysis under controlled environment (controlled $\mathrm{RH}$ and temperature); E: Young's modulus; E': Storage modulus; RH: Relative humidity.

\section{Acknowledgements}

The authors are thankful to Dr. John Duncan for his help with the DMA and Dr. Romain Bordes and Dr. Oleksandr Nechyporchuk for providing with the nanocellulose dispersion and their support. This study was supported by a co-funding from the H2020 Nanorestart European Project and the Engineering and Physical Sciences Research Council (EPSRC) through the Centre for Doctoral Training In Science and Engineering in Arts, Heritage and Archeaology (SEAHA).

\section{Authors' contributions}

$A B$ conceived and designed the experiments, carried out the experiments and wrote the first draft of the paper. MO supervised the research and helped in designing the research. ANT applied consolidant treatments and provided conservation-related information. AC supervised the research $L B$ supervised the research. All authors contributed to data interpretation and provided corrections to the manuscript and approved the final paper. All authors read and approved the final manuscript. 


\section{Funding}

This research was funded by the European Union's Horizon 2020 research and innovation programme under Grant agreement No 646063 (NanoRestArt) and the Engineering and Physical Sciences Research Council (EPSRC) through the Centre for Doctoral Training In Science and Engineering in Arts, Heritage and Archaeology (SEAHA)

\section{Availability of data and materials}

The datasets used and analysed during the current study are available from the corresponding author on reasonable request.

\section{Competing interests}

The authors declare that they have no competing interests.

\section{Author details}

${ }^{1}$ Eastman Dental Institute University College London, 256 Grays Inn Rd, London WC1X 8LD, UK. ${ }^{2}$ Getty Conservation Institute, 1200 Getty Center Dr \#700, Los Angeles, CA 90049, USA. ${ }^{3}$ Department of Arts and Conservation Department, Faculty of Fine Arts, University of Barcelona, C/Pau Gargallo, 4, 08028 Barcelona, Spain. ${ }^{4}$ Atelier Aurélia Chevalier, 289, rue Saint-Jacques, 75005 Paris, France. ${ }^{5}$ Department of Biological Sciences Birkbeck, University of London, Malet St, London WC1E 7HX, UK. ${ }^{6}$ Faculty of Dentistry, University of Toronto, 124 Edward Street, Toronto, ON M5G 1G6, Canada.

Received: 20 December 2019 Accepted: 16 May 2020

Published online: 03 June 2020

\section{References}

1. Ackroyd P, Phenix A, Villers C. Not lining in the twenty-first century: attitudes to the structural conservation of canvas paintings. Conservator. 2002:26(1):14-23. https://doi.org/10.1080/01410096.2002.9995172.

2. Mehra VR. Further develoments in cold lining (nap-bond system). In ICOM Triennal Meeting, 4th Venise. International Council of Museums Paris; 1975. p. 90.

3. Berger, G. A. (1970). New adhesive for the consolidation of paintings, drawings and textiles. Bulletin of the American Group. International Institute of Conservation of Historic and Artistic Works, 11(1); p. 36-38.

4. Hedley G. Relative humidity and the stress/strain response of canvas paintings: uniaxial measurements of naturally aged samples. Stud Conserv. 1988;33(3):133-48. https://doi.org/10.2307/1506206.

5. Oriola M, Campo-Francés G, Ruiz-Recasens C, Nualart-Torroja A. Canvas consolidation survey and treatment requirements for the NANORESTART project. Survey conducted by M. Oriola at University of Barcelona, private communication, unpublished results. 2019.

6. Bergeon S. "Science et patience" ou la restauration des peintures (Reunion de) . Paris: Ministère de la culture, de la communication, des grands travaux et du Bicentenaire; 1990. p.64.

7. Berger GA, Russell W. Conservation of paintings: research and innovations. Russel. London: Archetype Publications Ltd; 2000. p. 26.

8. De Luca D. I manufati dipinti su supporto tessile. Vademecum per allievi restauratori. II Prato, 2012. p. 85.

9. Stoner JH, Rushfield R. Conservation of easel paintings. Conservation of easel paintings. Abingdon: Routledge; 2013. p. 406

10. Erhardt D, Mecklenburg M. Relative humidity re-examined. Stud Conserv. 1994:39(2):32-8. https://doi.org/10.1179/sic.1994.39.supplement-2.32.

11. Hedley $\mathrm{G}$. The effect of beeswax/resin impregnation on the tensile properties of canvas. In: ICOM, editors. Icom committee for conservation. 4th triennial meeting. Paris; 1975.

12. Mecklenburg MF. Some aspects of the mechanical behaviour of fabric supported paintings'. Washington, D.C.: Report to the Smithsonian Institution; 1982.

13. Young $C$, Ackroyd P. The mechanical behaviour and environmental response of paintings to three types of lining treatment. National Gallery Tech Bull. 2001:22:85-104.

14. Young CRT, Hibberd RD. Biaxial tensile testing of paintings on canvas. Stud Conserv. 1999;44(2):129-41. https://doi.org/10.1179/ sic.1999.44.2.129.

15. Berger Gustav A. Testing adhesives for the consolidation of paintings. Stud Conserv. 1972;17(17):173-94
16. Bianco L, Avalle M, Scattina A, Croveri P, Pagliero C, Chiantore O. A study on reversibility of BEVA ${ }^{\circledR} 371$ in the lining of paintings. J Cult Heritage. 2015:16(4):479-85.

17. Roche A. Approche du principe de réversibilité des doublages des peintures sur toile. Stud Conserv. 2003;48(2):83-94.

18. McGlinchey C, Ploeger R, Colombo A, Simonutti R, Palmer M, Chiantore O de la Rie ER. Lining and consolidating adhesives: some new developments and areas of future research. Adhesives and consolidants for Conservation: research and applications. Ottawa: Canadian Conservation Institute; 2011.

19. Feller RL, Curran M, Bailie C. Photochemical studies of methacrylate coatings for the conservation of museum objects. In Photodegradation and photostabilization of coatings; 1981. p. 183-196. https://doi.org/10.1021/ bk-1981-0151.ch013.

20. Grassie N. Photodegradation of methacrylate/acrylate copolymers. Pure Appl Chem. 2008;34(2):247-58. https://doi.org/10.1351/pac1973340 20247.

21. Horie CV, Charles V. Materials for conservation : organic consolidants, adhesives and coatings/Nelson Horie. 2nd ed. Amsterdam, London: Butterworth-Heinemann; 2010.

22. Krarup Andersen C. Lined canvas paintings, mechanical properties and structural response to fluctuating relative humidity, exemplified by the collection of Danish Golden Age paintings at Statens Museum for Kunst (SMK). ACM SIGMultimedia records. Copenhagen!: Royal Danish Academy of Fine Arts; 2013. https://doi.org/10.1145/3300001.3300014.

23. Young C, Jardine S. Fabrics for the twenty-first century: as artist canvas and for the structural reinforcement of easel paintings on canvas. Stud Conserv. 2012;57(4):237-53. https://doi.org/10.1179/2047058412 y.0000000007.

24. Nechyporchuk O, Kolman K, Bridarolli A, Odlyha M, Bozec L, Oriola M, Bordes R. On the potential of using nanocellulose for consolidation of painting canvases. Carbohyd Polym. 2018;194:161-9. https://doi. org/10.1016/j.carbpol.2018.04.020.

25. Bridarolli A, Odlyha M, Nechyporchuk O, Holmberg K, Ruiz-Recasens $C$, Bordes R, Bozec L. Evaluation of the adhesion and performance of natural consolidants for cotton canvas conservation. ACS Appl Mater Interfaces. 2018;10(39):33652-61. https://doi.org/10.1021/acsam i.8b10727.

26. Hedley G. Measured opinions : collected papers on the conservation of paintings; edited by Caroline Villers. London: United Kingdom Institute for Conservation; 1993

27. Mehra VR. Comparative study of conventional relining methods and materials and research towards their improvement. In ICOM Committee for Conservation, 4th Triennial Meeting, Venice. Venice 1975.

28. Arslanoglu J. Aquazol as used in conservation practice by. WAAC Newslett. 2004;25(2):10-5.

29. Ploeger R, René De La Rie E, McGlinchey CW, Palmer M, Maines CA, Chiantore $O$. The long-term stability of a popular heat-seal adhesive for the conservation of painted cultural objects. Polym Degrad Stab. 2014;107:307-13. https://doi.org/10.1016/j.polymdegradstab 2014.01.031.

30. Ropret P, Zoubek R, Škapin AS, Bukovec P. Effects of ageing on different binders for retouching and on some binder-pigment combinations used for restoration of wall paintings. Mater Characterization. 2007;58(1112):1148-59. https://doi.org/10.1016/j.matchar.2007.04.027.

31. Ploeger R, McGlinchey CW, de la Rie ER. Original and reformulated BEVA (B) 371: composition and assessment as a consolidant for painted surfaces. Stud Conserv. 2014;60(4):217-26. https://doi.org/10.1179/2047058414 y.0000000132.

32. Rose C, von Endt DW. Protein chemistry for conservators (American i). Washington, D.C. 1984.

33. Nechyporchuk O, Yu J, Nierstrasz VA, Bordes R. Cellulose nanofibril-based coatings of woven cotton fabrics for improved inkjet printing with a potential in e-textile manufacturing. ACS Sust Chem Eng. 2017;5(6):4793801. https://doi.org/10.1021/acssuschemeng.7b00200.

34. Chung Y. Storage and management of paper and textile objects. In: Kyushik L, Eeun Y, editors. Conservation of papers and textiles. Daejeon: National Research Institute of Cultural Heritage; 2011. p. 324.

35. Haslach HW. Mechanics of moisture accelerated tensile creep in paper. Tappi J. 1994;77(10):179-86. 
36. Wojciech M, MaciejT. Color difference Delta E-a survey. Machine graphics and vision. 2011; 20(4), 383-411. http://mgv.wzim.sggw.pl/MGV20 .htm/\%0Ahttp://www.researchgate.net/publication/236023905_Color _difference_Delta_E_-_A_survey.

37. Mecklenburg Marion F. Determining the acceptable ranges of relative humidity and temperature in museums and galleries, part 1. Suitland: Structural Response to Relative Humidity; 2007.

38. Arroyo CPG. Finite element modeling of vibrations in canvas paintings. Netherlands: University TU Delft; 2013. p. 23.

39. Apolinario G, lenny P, Corn S, Léger R, Bergeret A, Haudi JM. Effects of water ageing on the mechanical properties of flax and glass fibre composites: degradation and reversibility. Natural fibres: advances in science and technology towards industrial applications (RILEM Book). Springer: Dordrecht; 2016. pp. 183-196. https://doi. org/10.1007/978-94-017-7515-1_14.

40. Célino A, Fréour S, Jacquemin F, Casari P. The hygroscopic behavior of plant fibers: a review. Front Chem. 2014;1(43):1-43. https://doi. org/10.3389/fchem.2013.00043.

41. Okubayashi S, Griesser UJ, Bechtold T. A kinetic study of moisture sorption and desorption on lyocell fibers. Carbohyd Polym. 2004;58(3):293-9. https ://doi.org/10.1016/j.carbpol.2004.07.004.

42. Symington MC, Banks WM, West OD, Pethrick RA. Tensile testing of cellulose based natural fibers for structural composite applications. J Compos Mater. 2009. https://doi.org/10.1177/0021998308097740.
43. Bowditch MR. The durability of adhesive joints in the presence of water. Int J Adhes Adhes. 1996;16(2):73-9. https://doi.org/10.1016/01437496(96)00001-2

44. Burchard W. Solubility and solution structure of cellulose derivatives. Cellulose. 2003;10(3):213-25. https://doi.org/10.1023/A:1025160620576.

45. von Endt DW, Baker MT. The chemistry of filled animal glue systems. In: Bigelow D, eds. Gilded wood conservation and history. Sound View Press: 1991. p. 155-162

46. Sehaqui $H$, de Larraya UP, Liu P, Pfenninger N, Mathew AP, Zimmermann T, Tingaut P. Enhancing adsorption of heavy metal ions onto bio based nanofibers from waste pulp residues for application in wastewater treatment. Cellulose. 2014;21(4):2831-44. https://doi.org/10.1007/s1057 0-014-0310-7.

47. Sehaqui H, Zhou Q, Ikkala O, Berglund LA. Strong and tough cellulose nanopaper with high specific surface area and porosity. Biomacromol. 2011;12(10):3638-44. https://doi.org/10.1021/bm2008907.

48. Banavath HN, Bhardwaj NK, Ray AK. A comparative study of the effect of refining on charge of various pulps. Biores Technol. 2011;102(6):4544-51. https://doi.org/10.1016/j.biortech.2010.12.109.

\section{Publisher's Note}

Springer Nature remains neutral with regard to jurisdictional claims in published maps and institutional affiliations.

\section{Submit your manuscript to a SpringerOpen ${ }^{\circ}$ journal and benefit from:}

- Convenient online submission

- Rigorous peer review

- Open access: articles freely available online

- High visibility within the field

- Retaining the copyright to your article

Submit your next manuscript at $\boldsymbol{\nabla}$ springeropen.com 